\title{
DEVELOPMENT OF NI-BASED SINGLE CRYSTALSUPERALLOYS FOR POWER-GENERATION GAS TURBINES
}

\author{
Ryokichi Hashizume ${ }^{1}$, Akira Yoshinari ${ }^{2}$, Takamasa Kiyono ${ }^{3}$,Yoshinori Murata ${ }^{4}$,Masahiko Morinaga ${ }^{4}$
}

1) Electric Power Substrate R\&D Department (Power Generation), Power Engineering R\&D Center, The Kansai Electric Power Company Inc., 11-20 Nakoji 3-chome, Amagasaki 661- 0974, JAPAN; hasizume@ rdd.kepco.co.jp

2) Hitachi Research Laboratory, Hitachi Co. Ltd., 7-1-1 Ohmika-cho, Hitachi, Ibaraki 319-1292, JAPAN

3) Thermal \& Hydroelectric Systems Div, Hitachi Co. Ltd., 6 Kanda-Surugadai 4-chome, Chiyoda-ku, Tokyo, 101-8010 JAPAN

4) Department of Materials Science and Engineering, Graduate School of Engineering, Nagoya University, Furo-cho, Chikusa, Nagoya 464-8603, JAPAN

Keywords: Gas turbine, d-electrons concept, single-crystal, creep strength, oxidation resistance, burner rig test, hot corrosion resistance,

\begin{abstract}
In advanced industrial gas-turbine systems, there has been a great demand for new single crystal (SC) superalloys with an excellent combination of high-temperature creep strength, hot-corrosion resistance and oxidation resistance. In this study, ten nickel-based SC superalloys were designed with the aid of the d-electrons concept. Their chemical compositions were in the range of 1.2$1.5 \% \mathrm{Ti}, 3.8-6.5 \% \mathrm{Cr}, 11 \% \mathrm{Co}, 0-1.4 \% \mathrm{Mo}, 6.5-7.4 \% \mathrm{Ta}, 5.0-6.0 \% \mathrm{~W}$, 3.6-5.4\% Re, 5.1-5.5\% Al, 0.12-0.14\% Hf and balanced $\mathrm{Ni}$ in wt\%. A series of experiments such as creep rupture tests, burner rig tests and cyclic oxidation tests were conducted with the heattreated SC specimens of these alloys. All the designed alloys were found to be superior in creep rupture life to a second generation superalloy currently used in the world. In the hot-corrosion resistance estimated from the burner rig tests, any designed alloys were comparable or even superior to a second generation superalloy. The oxidation resistance was very different among the designed alloys, but some of them showed better resistance than a second generation superalloy. Thus the SC alloys containing about $4-5 \mathrm{wt} \% \mathrm{Re}$ had about $20^{\circ} \mathrm{C}$ higher temperature capability than the second generation superalloy, while exhibiting excellent hotcorrosion resistance and oxidation resistance.
\end{abstract}

\section{Introduction}

There has been a great demand for the advanced combined cycle system for power generation. This system has not only a great potential of power generation with lower cost, but also a high possibility of decreasing the emission of carbon dioxide because of its higher fuel efficiency. Needless to say, the gas turbine inlet temperature should increase to improve the thermal efficiency of the system. Recently, the inlet temperature has been approaching $1800 \mathrm{~K}$. In order to increase the gas firing temperature further, there is a strong need to develop new superalloys with excellent heat resistant properties.

Nickel-based superalloys used for the combined cycle system should be superior in both the hot corrosion resistance and the oxidation resistance compared to the superalloys used for jet engines. This is because the total service duration is much longer in this system than in the jet engine of the aircraft, and also the maintenance cost should be kept lower to sustain electricity price at a reasonable level. Another reason is partially due to the location of the power plant since it is often placed near seaside, particularly in Japan. There is a strong attack to the system when exposed to the $\mathrm{NaCl}$ corrosive atmosphere.

A single crystal (SC) superalloy was first used for the blade in jet engines of the aircraft in the second half of the 1970s, and since then many single crystal superalloys have been developed. For convenience, depending on the Re content, they are classified into the 1st generation, 2nd generation and 3rd generation SC superalloys, each containing $0 \mathrm{wt} \% \mathrm{Re}$, about $3 \mathrm{wt} \% \mathrm{Re}$ and about $6 \mathrm{wt} \% \mathrm{Re}$, respectively [1-4]. Among these, only the 2nd generation SC superalloys have been used for the powergeneration gas turbines, and as yet no 3rd generation SC superalloys have been used commercially despite their excellent creep strength at high temperatures. The reasons can be summarized as follows:

1) It is difficult to grow a large single crystal blade which does not contain any grain defects in conventional casting experiments.

2) The oxidation resistance at high temperatures is much poorer as compared to that of the 2 nd generation superalloys.

3) The phase stability is also poor at high temperatures, so that the TCP phases tend to form in the alloy and the formation can cause the degradation of long time properties, which are critical for power generation gas turbines.

In this study, we have designed ten different superalloys using the d-electrons concept to solve these problems, and conducted a series of experiments to examine their creep strength, hot corrosion resistance and oxidation resistance as well. We have previously succeeded in finding alloys with high creep strength and good hot corrosion resistance [5]. So, this time we have tried to develop those alloys which possess higher oxidation resistance than the 2nd generation superalloys. For this purpose, the contents of $\mathrm{Cr}, \mathrm{Mo}, \mathrm{W}$ and $\mathrm{Ta}$ were optimized in the 4-5 wt $\% \mathrm{Re}$ containing superalloys. Some alloys did not contain Mo, because Mo is known to deteriorate oxidation resistance. It will be shown that some of the designed SC alloys had an excellent combination of high creep strength, hot corrosion resistance, extremely good oxidation resistance and good castability. 
Table 1. Chemical compositions and alloying parameters of experimental alloys (wt\%).

\begin{tabular}{|c|c|c|c|c|c|c|c|c|c|c|c|c|}
\hline & $\mathrm{Ti}$ & $\mathrm{Cr}$ & $\mathrm{Co}$ & $\mathrm{Ni}$ & Mo & Hf & $\mathrm{Ta}$ & W & $\mathrm{Re}$ & $\mathrm{Al}$ & $\overline{M d}$ & $\overline{B O}$ \\
\hline A & 1.4 & 4.0 & 11.0 & Bal. & -- & 0.12 & 6.8 & 5.5 & 4.4 & 5.4 & 0.978 & 0.650 \\
\hline B & 1.4 & 6.0 & 11.0 & Bal. & -- & 0.12 & 6.8 & 5.5 & 4.4 & 5.4 & 0.987 & 0.668 \\
\hline $\mathrm{D}$ & 1.4 & 5.0 & 11.0 & Bal. & -- & 0.12 & 7.4 & 5.5 & 3.6 & 5.4 & 0.984 & 0.658 \\
\hline $\mathrm{E}$ & 1.4 & 6.5 & 11.0 & Bal. & -- & 0.12 & 7.4 & 5.0 & 3.6 & 5.4 & 0.988 & 0.669 \\
\hline $\mathrm{F}$ & 1.4 & 5.0 & 11.0 & Bal. & -- & 0.12 & 6.8 & 6.4 & 4.4 & 5.3 & 0.985 & 0.664 \\
\hline $\mathrm{H}$ & 1.2 & 4.0 & 11.0 & Bal. & 0.8 & 0.12 & 6.8 & 6.0 & 5.2 & 5.5 & 0.987 & 0.661 \\
\hline I & 1.5 & 4.0 & 11.2 & Bal. & 0.6 & 0.14 & 6.7 & 5.5 & 5.4 & 5.3 & 0.985 & 0.661 \\
\hline $\mathrm{J}$ & 1.5 & 3.8 & 11.0 & Bal. & 1.4 & 0.14 & 6.7 & 5.3 & 5.4 & 5.1 & 0.988 & 0.667 \\
\hline $\mathrm{K}$ & 1.0 & 6.5 & 9.0 & Bal. & 0.6 & 0.10 & 6.5 & 6.0 & 3.0 & 5.6 & 0.984 & 0.664 \\
\hline $\mathrm{L}$ & 0.7 & 6.6 & 9.2 & Bal. & 0.5 & 1.40 & 3.2 & 8.5 & 3.0 & 5.7 & 0.983 & 0.664 \\
\hline
\end{tabular}

\section{$\underline{\text { Alloy Chemistry }}$}

\section{Experimental Procedure}

Ten nickel-based SC superalloys containing Ti-(3.8-6.5)Cr-CoHf(-Mo)-Ta-W-(3.6-5.4)Re-Al-Ni were designed with the aid of the d-electrons concept. Their chemical compositions are listed in Table1. The d-electrons concept has been devised on the basis of the molecular orbital calculation of electric structures [6]. In this concept both the Md and Bo parameters are used, where Md is the d-orbital energy level of alloying element and Bo is the bond order between alloying element and $\mathrm{Ni}$ atoms. One advantage of using this concept is to predict precisely the alloying limits of refractory elements in view of the phase stability even in high $\mathrm{Re}$ containing superalloys [7]. This prediction method is known as New PHACOMP [8-11]. Also, the volume fraction of the $\gamma$ ' phase in the alloy is predictable using these parameters [12].

Both the $\overline{M d}$ and the $\overline{B o}$ values for the designed alloys are shown in the Table1. They were obtained from the compositional average of the d-electron parameters, Md and Bo. The compositions of the refractory elements such as $\mathrm{Cr}$, Mo, W and Ta in the alloys were adjusted so that the $\overline{M d}$ and $\overline{B o}$ values lay in the range of $\overline{M d}: 0.97-0.99, \overline{B o}: 0.65-0.67$, since the target region for alloy design is located in this range [3]. Also, in the $\overline{M d}-\overline{B o}$ map shown in Fig. 1, the ten designed alloys are nearer to the 2nd generation SC superalloys than the 3rd generation SC superalloys. In Table 1, six alloys of A thru F are Mo-free alloys, designed so as to raise the oxidation resistance. Alloys $\mathrm{K}, \mathrm{L}$, and $\mathrm{M}$ are reference alloys; Alloy $\mathrm{K}$ is the 2 nd generation SC superalloy with the same composition as CMSX-4. Alloy L is the 2nd generation DS alloy with the same composition as CM186LC. Alloy M is the 3rd generation SC alloy developed in Japan, TMS-75.

\section{Alloy Preparation and Heat Treatments}

First, the master ingots of these alloys were made in a vacuum induction furnace by controlling the contents of gas elements to be as low as possible. Then, using those ingots, single crystals $15 \mathrm{~mm}$ in diameter and $180 \mathrm{~mm}$ in length were grown by a directionally solidified method. The conditions of solution heat treatment and aging heat treatment are listed in Table 2. Every specimen was first heat treated following the conditions shown in Table 2 and then supplied for a series of experiments.
Table 2. Heat treatment conditions employed in this study.

\begin{tabular}{|c|c|c|c|}
\hline Alloy & Solution & 1st Step aging & 2nd Step aging \\
\hline $\mathrm{A}$ & \multirow{5}{*}{$\begin{array}{l}1573 \mathrm{~K} / 4 \mathrm{~h}+1583 \mathrm{~K} / 6 \mathrm{~h} \\
+1588 \mathrm{~K} / 12 \mathrm{~h}\end{array}$} & $1433 \mathrm{~K} / 4 \mathrm{~h}, \mathrm{AC}$ & \multirow{5}{*}{$1144 \mathrm{~K} / 20 \mathrm{~h}, \mathrm{AC}$} \\
\hline $\mathrm{B}$ & & $1413 \mathrm{~K} / 4 \mathrm{~h}, \mathrm{AC}$ & \\
\hline $\mathrm{C}$ & & \multirow{3}{*}{$1433 \mathrm{~K} / 4 \mathrm{~h}, \mathrm{AC}$} & \\
\hline $\mathrm{D}$ & & & \\
\hline $\mathrm{E}$ & & & \\
\hline $\mathrm{F}$ & \multirow{2}{*}{$\begin{array}{l}1573 \mathrm{~K} / 8 \mathrm{~h}+1583 \mathrm{~K} / 4 \mathrm{~h} \\
+1588 \mathrm{~K} / 8 \mathrm{~h}\end{array}$} & \multirow[t]{2}{*}{$1433 \mathrm{~K} / 4 \mathrm{~h}, \mathrm{AC}$} & \multirow[t]{2}{*}{$1144 \mathrm{~K} / 20 \mathrm{~h}, \mathrm{AC}$} \\
\hline $\mathrm{G}$ & & & \\
\hline $\mathrm{H}$ & \multirow{2}{*}{$\begin{array}{l}1593 \mathrm{~K} / 12 \mathrm{~h}+1598 \mathrm{~K} / 12 \mathrm{~h} \\
+1603 \mathrm{~K} / 24 \mathrm{~h}\end{array}$} & \multirow[t]{2}{*}{$1393 \mathrm{~K} / 4 \mathrm{~h}, \mathrm{AC}$} & \multirow[t]{2}{*}{$1144 \mathrm{~K} / 20 \mathrm{~h}, \mathrm{AC}$} \\
\hline $\mathrm{I}$ & & & \\
\hline $\bar{J}$ & $\begin{array}{l}1573 \mathrm{~K} / 12 \mathrm{~h}+1583 \mathrm{~K} / 12 \mathrm{~h} \\
+1593 \mathrm{~K} / 24 \mathrm{~h}\end{array}$ & $1433 \mathrm{~K} / 4 \mathrm{~h}, \mathrm{AC}$ & $1144 \mathrm{~K} / 20 \mathrm{~h}, \mathrm{AC}$ \\
\hline
\end{tabular}

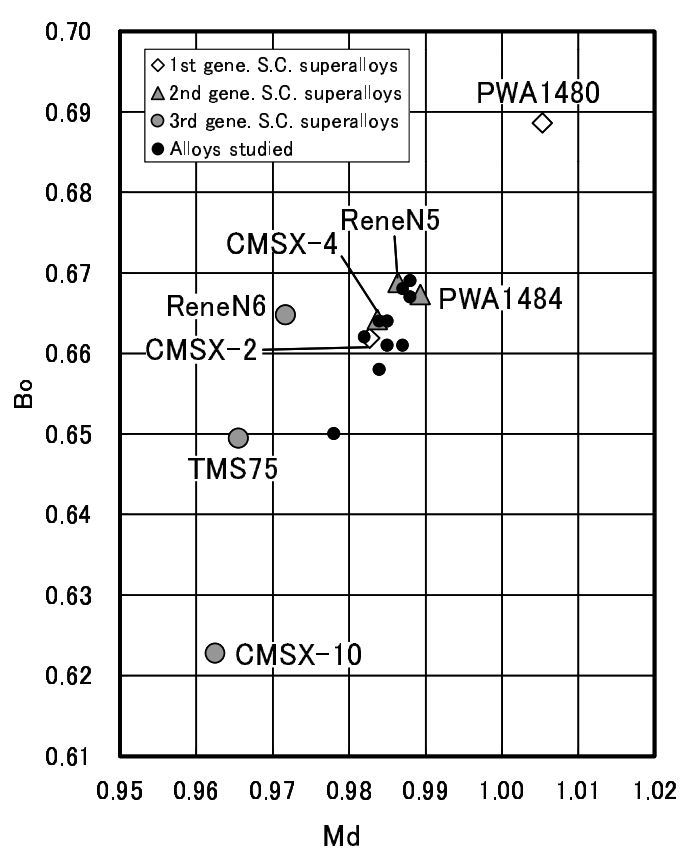

Fig. 1. $\overline{M d}-\overline{B o}$ map showing the location of the ten designed alloys, the 2nd generation SC superalloys and the 3rd generation SC superalloys. 


\section{$\underline{\text { Microstructural Observation }}$}

The microstructures in the SC alloys were observed with SEM before and after the creep rupture tests. The cross section of the specimens after a hot corrosion test and oxidation tests were also observed using a SEM equipped with the EDX analyzer. For these observations, the specimen surface was first polished mechanically with emery papers and then with a buff dripping water containing $\mathrm{Al}_{2} \mathrm{O}_{3}$ powders. Subsequently, the surface was etched chemically in an $\mathrm{HCl}-\mathrm{HNO}_{3}$ solution.

\section{$\underline{\text { Creep Rupture and Tensile Test }}$}

The heat-treated SC alloys were machined mechanically into the specimens for the creep rupture tests and the tensile tests. The gauge length of the specimen was $6 \mathrm{~mm}$ in diameter and $30 \mathrm{~mm}$ in length. These tests were performed following the standard of ASTM-E139. The tensile tests were carried out at room temperature and $973 \mathrm{~K}$ with the strain rate of $5.56 \times 10^{-5} / \mathrm{s}$. The creep rupture tests were performed under the temperature/stress conditions of $1313 \mathrm{~K} / 137 \mathrm{MPa}, 1255 \mathrm{~K} / 206 \mathrm{MPa}, 1193 \mathrm{~K} / 314 \mathrm{MPa}$, $248 \mathrm{MPa}, 206 \mathrm{MPa}$, and $1123 \mathrm{~K} / 441 \mathrm{MPa}$.

\section{$\underline{\text { Oxidation and Hot Corrosion Test }}$}

The plate specimens with the size $10 \times 25 \times 1.5 \mathrm{~mm}$ were cut from the SC alloys by an electro-spark machine. Two kinds of oxidation tests were employed in this study. One was the cyclic oxidation test, in which the specimen was held in air at $1373 \mathrm{~K}$ for 20 hours followed by air cooling in each cycle. This cycle was repeated 12 times, so the total exposure time at $1373 \mathrm{~K}$ was 240hours. The other was the continuous oxidation test at $1313 \mathrm{~K}$ for 3,600 hours and at $1193 \mathrm{~K}$ for 10,000 hours.

In order to examine the hot corrosion resistance of the SC alloys, a burner-rig test was carried out at $1173 \mathrm{~K}$ for 35 hours with specimens of $8 \mathrm{~mm}$ in diameter and $30 \mathrm{~mm}$ in length. The burning gas was prepared by using a fuel containing $0.04 \%$ sulfur and the atomized brine of $80 \mathrm{ppm} \mathrm{NaCl}$.

\section{Single Crystal Casting of a Model Bucket}

The casting test was carried out with a model bucket for the first stage of $25 \mathrm{MW}$ class gas turbine. The model bucket was $170 \mathrm{~mm}$ long, and there was a return-flow type cooling structure inside it.

\section{Experimental Results}

\section{$\underline{\text { Microstructure }}$}

The microstructures of all the designed alloys after the 2nd step aging are shown in Fig. 2. While every alloy appeared to have a similar uniform $\gamma / \gamma^{\prime}$ phase microstructure, but still there was a little difference in the aspect and the size of the $\gamma^{\prime}$ phase among the alloys. The shape of the $\gamma^{\prime}$ phase in the alloys $\mathrm{A}$ and $\mathrm{H}$ was partially irregular. The size of the $\gamma^{\prime}$ phase was about $0.5 \mu \mathrm{m}$ in alloys A thru E, and about $0.3-0.4 \mu \mathrm{m}$ in alloys $\mathrm{F}$ thru J. Thus, the Mo-free alloys A thru E (except for alloy F) had the larger $\gamma$, phase as compared to the Mo-containing alloys $\mathrm{G}$ and $\mathrm{H}$. Besides this, no correlation was found between the microstructure and the chemical compositions of the alloys.



Fig. 2. SEM micrographs of round bar specimens after the aging heat treatment. 


\section{$\underline{\text { Tensile Strength }}$}

The results of the tensile tests at room temperature and $973 \mathrm{~K}$ are shown in Fig. 3 and Fig. 4, respectively. The tensile strength at room temperature was in the range of 950 to $1100 \mathrm{MPa}$ for the designed alloys, A thru $\mathrm{J}$ and the reference alloys, $\mathrm{K}$ thru $\mathrm{M}$, which is sufficient strength for the turbine blade. Also, for the designed alloys, the $0.2 \%$ proof strength and the tensile strength at $973 \mathrm{~K}$ were in the range of 950 to $1100 \mathrm{MPa}$ and 1150 to $1300 \mathrm{MPa}$ respectively. The strength was higher at $973 \mathrm{~K}$ than at room temperature. Also, it was slightly higher in the designed alloys than the reference alloys.

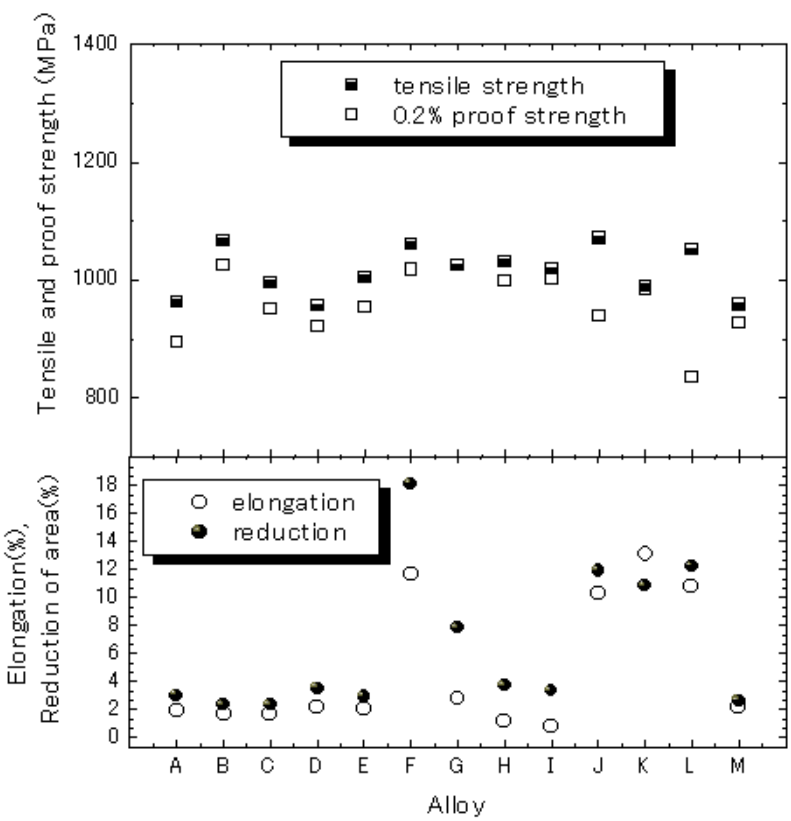

Fig. 3. Results of the tensile tests at room temperature.

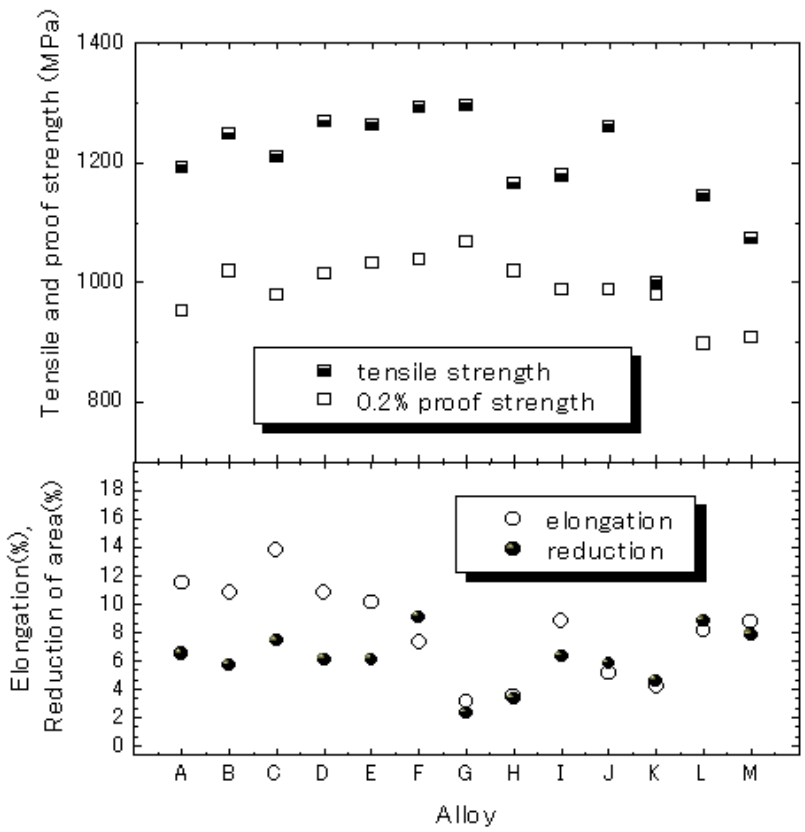

Fig. 4. Results of the tensile tests at $973 \mathrm{~K}$.

\section{Creep Strength}

The results of the creep rupture tests are shown in Fig. 5. The measured creep strength of the designed alloys varied to some degree depending on the chemical compositions. As for the creep condition of $1313 \mathrm{~K}, 137 \mathrm{MPa}$, the creep rupture life of the designed alloys, except for alloys A, C, D, J, exceeded 1000 hours, which was much longer than the rupture life, 726 hours, of the 2nd generation superalloy (alloy K). As for the creep condition of $1193 \mathrm{~K}, 206 \mathrm{MPa}$, which is probably a similar condition that the gas turbine blade would experience during service, the creep rupture life of the designed alloys except for the alloys A, C, F was about 1.4 times longer than that of the 2 nd generation superalloy, and nearly equaled the rupture life, 7329 hours, of the 3rd generation SC superalloy (alloy M). Thus, it can be said that the creep rupture strength of the designed alloys is at a very high level. Although alloys A thru F contained no Mo, the creep strength was comparable to that of alloy $\mathrm{G}$ containing $0.5 \% \mathrm{Mo}$. Also, alloy B contained $4.4 \% \mathrm{Re}$ and alloy $\mathrm{C}$ contained $3.6 \% \mathrm{Re}$, and the rest of the alloy compositions were almost same between them. So, the difference in the measured creep strength between them is attributable to the differences in the Re content. Alloys $\mathrm{H}$, I and J showed relatively higher creep strength among the designed alloys. This result may also be interpreted as due to the Re content, since these alloys contained 5.2-5.4\% Re but the other alloys contained 3.6-4.4\% Re. In addition, alloy $\mathrm{J}$ had the highest Mo and Re contents (e.g., 1.4\% Mo and 5.4\% Re) among alloys $\mathrm{H}$, I and J, but it showed weaker creep strength than alloys H and I. In this case, it seemed that Mo played no significant role on the improvement of the creep strength at high temperatures.

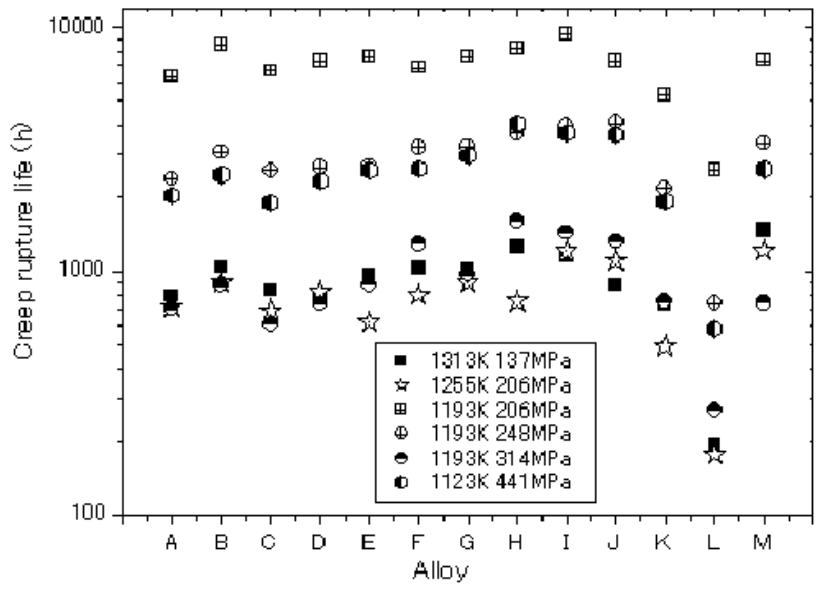

Fig. 5 Results of creep rupture tests.

\section{$\underline{\text { Hot Corrosion Resistance }}$}

The results of mass changes in the hot corrosion test are shown in Fig. 6 for the designed alloys and the reference alloys. This burner rig test was performed at $1173 \mathrm{~K}$ for 35 hours. Every designed alloy exhibited good hot-corrosion resistance, and their mass change was comparable to or even smaller than that of CMSX-4. For example, the mass change of alloys $\mathrm{F}$ and $\mathrm{G}$ was very small $\left(0.0\right.$ to $\left.-0.2 \mathrm{mg} / \mathrm{cm}^{2}\right)$. Also, it was $0.80 \mathrm{mg} / \mathrm{cm}^{2}$ for alloy B, and less than $1.52 \mathrm{mg} / \mathrm{cm}^{2}$ for the other designed alloys except for alloy D. Alloy D exhibited the largest mass change, $1.86 \mathrm{mg} / \mathrm{cm}^{2}$, among the designed alloys, but still its magnitude was comparable to that 
of CMSX-4. On the other hand, the mass changes of the two reference alloys, CM186LC and the 3rd generation superalloy, were larger than $10 \mathrm{mg} / \mathrm{cm}^{2}$. In case of the $14 \% \mathrm{CrCC}$ alloy, which is a practically used material for the first stage blade of $1300^{\circ} \mathrm{C}$ TRIT power generation gas turbine, the mass change was $-1.9 \mathrm{mg} / \mathrm{cm}^{2}$, because the corroded scale that formed on the surface flaked off.

The photos of the specimens after the burner rig test are shown in Fig.7 for the four designed alloys, B, F, H, I, and also the four reference alloys. The corroded surface of these designed alloys appeared smooth and the surface was covered with thin scales. In contrast to these designed alloys, two of the reference alloys, CM186LC and TMS-75, showed a very rough surface covered with thick and ragged corroded scales, indicating that the hotcorrosion resistance was extremely poor in these alloys. On the other hand, there was no such ragged corroded scales on the surface of the $14 \% \mathrm{CrCC}$ alloy, probably due to the flaking off of the scales, as explained earlier.

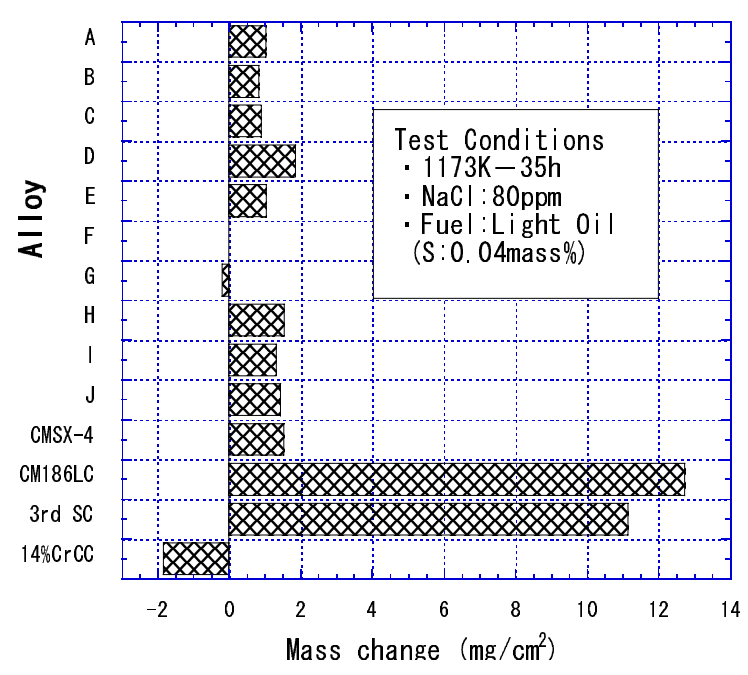

Fig.6. Results of hot corrosion burner rig tests.

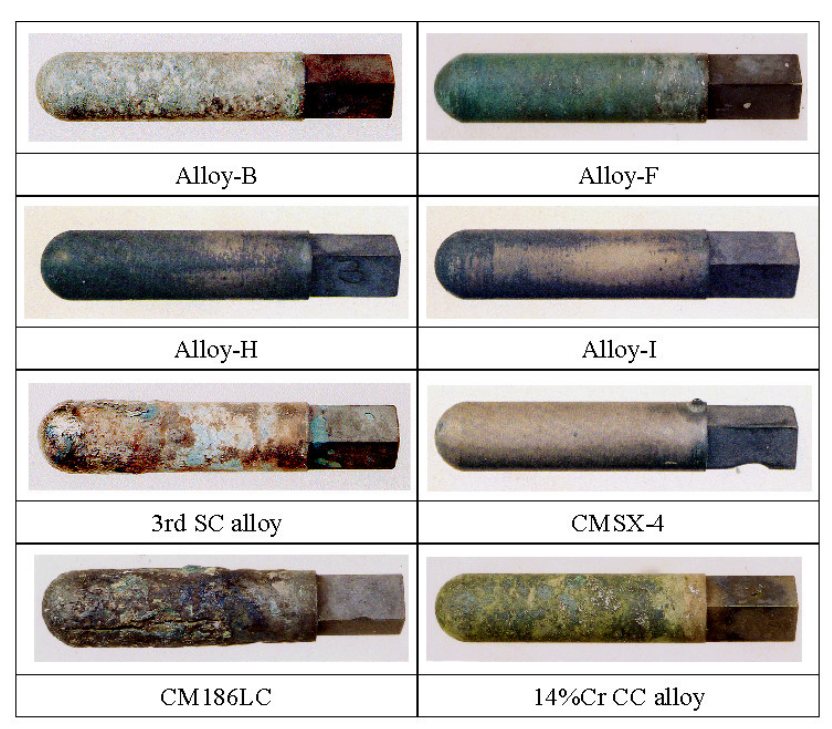

Fig.7. Photos of test specimens after hot corrosion burner rig tests.

\section{Oxidation Resistance}

The results of mass changes during the continuous oxidation at $1193 \mathrm{~K}$ are shown in Fig. 8. There were no large differences among the designed alloys except for the three designed alloys, $\mathrm{H}$, $\mathrm{I}$ and $\mathrm{J}$. The measured mass changes of the majority of designed alloys were as small as about $+1 \mathrm{mg} / \mathrm{cm}^{2}$ even after the oxidation test for 10,000 hours. On the other hand, the mass change of the reference alloy $\mathrm{N}$, namely $14 \% \mathrm{CrCC}$ alloy, was as large as $35 \mathrm{mg} / \mathrm{cm}^{2}$. As for the reference alloy M, namely TMS-75, the mass change became significant after 5000 hours and then it kept increasing with exposure time. The mass change measured after 10,000 hours was about $-6 \mathrm{mg} / \mathrm{cm}^{2}$.

The results of the continuous tests at $1313 \mathrm{~K}$ and the cyclic tests at 1373K are shown in Fig. 9 and Fig. 10, respectively. Being different from the results of the continuous oxidation tests at $1193 \mathrm{~K}$ shown in Fig. 8, the mass changes varied among the designed alloys, and the alloys were divided roughly into two groups. One was the group of the Mo-free alloys, A thru F, and the other was the group of the Mo-containing alloys, G and $\mathrm{H}$. At both temperatures of $1313 \mathrm{~K}$ and $1373 \mathrm{~K}$, it was found that the mass changes were smaller in the Mo-free alloys than the Mocontaining alloys. Thus, as might be expected from the detrimental effect of Mo, the Mo-free alloys had better oxidation resistance than the Mo-containing alloys. Also, the reference alloy K (CMSX-4) and alloy L (CM186LC) exhibited very good oxidation resistance. In general the oxidation reaction becomes more active with increasing temperature, so that the cycle of forming oxidation scale, flaking off, and then forming new oxidation scale, will be accelerated with temperature, resulting in significant mass reduction. However, there was little mass change in alloys B and D, although these alloys showed a little mass gain in the beginning of the oxidation test. As shown in Table 1, the chemical compositions are quite similar among the Mo-free alloys, A thru $\mathrm{F}$, for example, their $\mathrm{Ti}, \mathrm{Co}$ and $\mathrm{Al}$ contents are equal, but only alloys $\mathrm{B}$ and $\mathrm{D}$ exhibited almost no mass change in the oxidation test at $1313 \mathrm{~K}$ and $1373 \mathrm{~K}$. The reason why the oxidation resistance was so different among these alloys despite a little difference in the chemical compositions, still remains unclear. But the present results will provide us a clue to the improvement of the oxidation resistance, so it is necessary to investigate the cause of this phenomenon in the future.

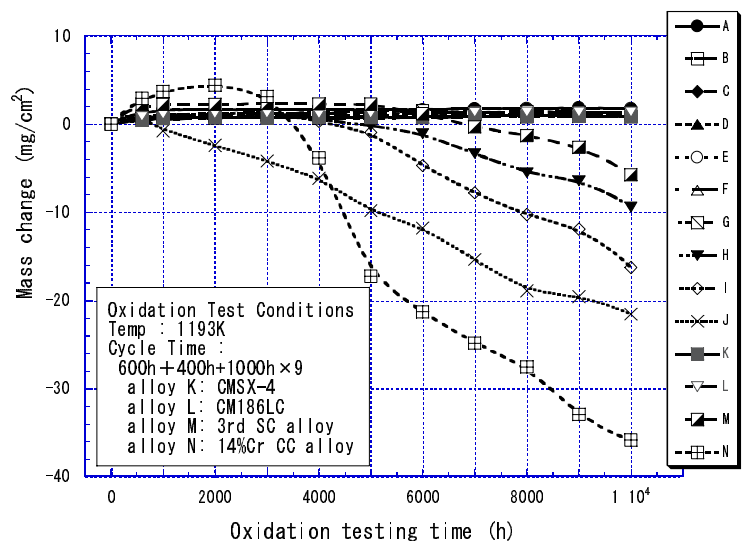

Fig. 8. Results of continuous oxidation tests at $1193 \mathrm{~K}$. 




Fig.9. Results of continuous oxidation tests at $1313 \mathrm{~K}$.

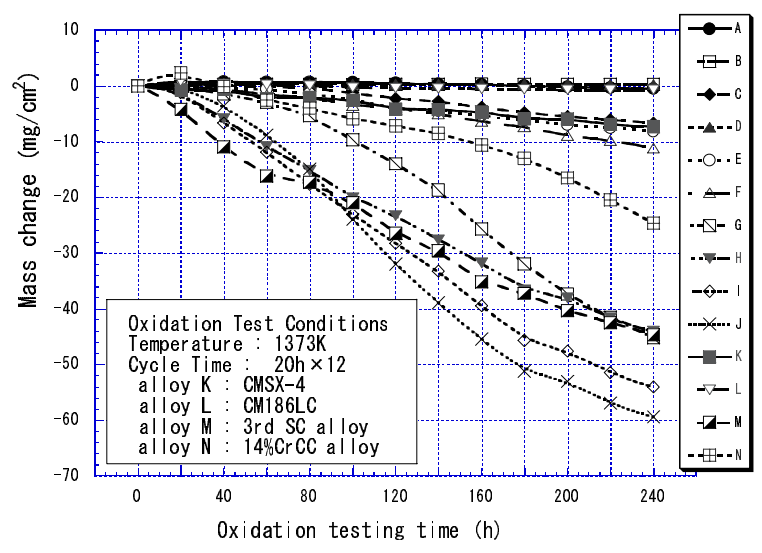

Fig.10. Results of cyclic oxidation tests at $1373 \mathrm{~K}$.

\section{$\underline{\text { Single Crystal Casting of a Model Bucket }}$}

It is well known that there is great difficulty in casting 3rd generation superalloys in a large size, gas turbine blades. This is because such superalloys contain a large amount of Re and its solute distribution coefficient is larger than one, namely $\mathrm{k}(\mathrm{Re})=2.14$. In this case, many freckles tend to form in the alloy.[18] In order to evaluate single crystal bucket castability, a casting test of alloy $\mathrm{F}$ was carried out using a model bucket for the first stage blade in the $25 \mathrm{MW}$ class gas turbine. We have successfully cast a SC model bucket with the length of $170 \mathrm{~mm}$. The overview is shown in Fig. 11. The model bucket was heattreated following the aging condition of alloy $\mathrm{F}$ shown in Table 2, and test pieces were cut from the single crystal bucket. The microstructure is shown in Fig. 12 together with the one obtained from the round bar specimen.

Although the size of the $\gamma^{\prime}$ phase of the model bucket was slightly larger than that of the round bar specimen, the microstructure still consisted of uniform $\gamma+\gamma^{\prime}$ phases. The reason why the $\gamma^{\prime}$ phase in the model bucket tended to be large is probably due to the fact that as the bucket was larger and thicker than the round bar specimen, the cooling rate of the bucket after the heat treatment was slower than that of the round bar specimen. It is, however, supposed that the creep strength of the bucket is nearly the same as the round bar specimen, since the creep strength of the Mo-free.

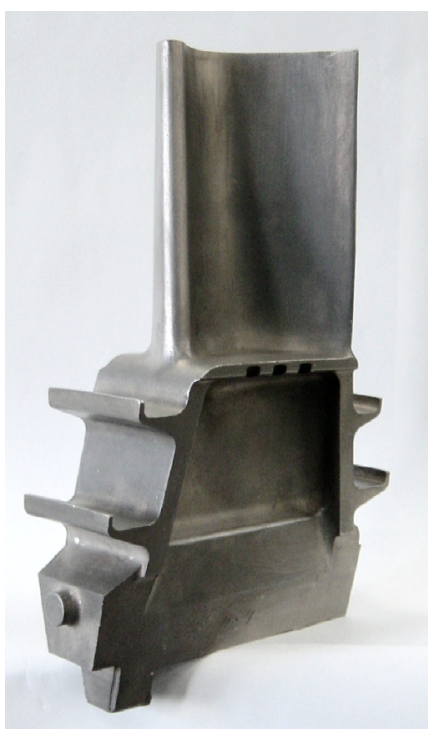

Fig.11. Overview of the single-crystal model bucket (length : $170 \mathrm{~mm}$ )

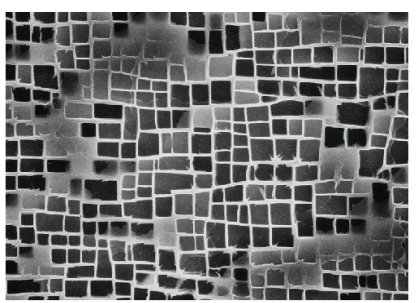

(a) model bucket

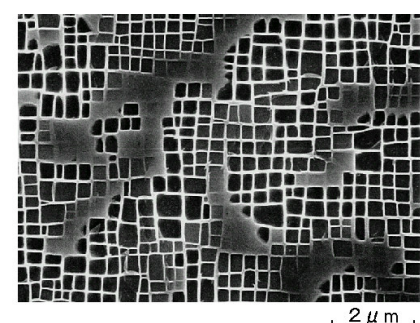

(b) round bar specimen
Fig.12. SEM micrographs showing the $\gamma / \gamma^{\prime}$ microstructure of the model bucket and the round bar specimen after aging.

alloys, A thru E, was still strong despite their larger $\gamma^{\prime}$ phase than the alloy $\mathrm{F}$ as shown in Fig. 2

\section{Discussion}

\section{Creep Strength}

Great efforts have been made to enhance the creep strength of the superalloys by controlling the volume fraction of the $\gamma$ 'phase and also by increasing the contents of refractory elements such as Mo, $\mathrm{W}, \mathrm{Re}$ and $\mathrm{Ta}$ in the alloy. In fact, the total $\mathrm{wt} \%$ of $(\mathrm{Mo}+\mathrm{W}+\mathrm{Re})$ in 3rd generation superalloys is typically more than $10 \%$. In addition, the lattice misfit between the $\gamma$ and $\gamma$ 'phases is controlled to be a proper value [13] and several SC superalloys have been developed along this approach [14]. The chemical compositions of the designed alloys in this study were first optimized by the delectron theory and then the contents of Cr, Mo, Ta, W and Re were varied by about $0.5 \%$ to optimize the oxidation resistance and the castability as well. Although it was found that the addition of Re yielded a beneficial effect on the creep strength, there was no extremely large difference in the creep strengths among the same Re content alloys.

The microstructures of the creep-ruptured specimens are shown in Fig. 13. The observed positions in the specimens were apart from the ruptured part by more than $10 \mathrm{~mm}$, so the microstructure was 
not affected strongly by the crystallographic rotation to occur near the ruptured part during creep. The clear rafted structures were observed in alloys $\mathrm{B}$ and $\mathrm{H}$ in the creep condition of $1123 \mathrm{~K}$ $441 \mathrm{MPa}$ and also in alloy $\mathrm{H}$ in the creep condition of $1313 \mathrm{~K}$ $137 \mathrm{MPa}$, but the other alloys did not show any clear rafted structures except for the deformed ones. It has been believed that if the structures with narrow and uniform rafts are formed during creep, the creep strength becomes high. But as for the present six designed alloys, such a correlation was never seen. Furthermore, the alloying of Mo has been believed to be effective in improving the creep strength, but this was not necessarily true according to the present results. This knowledge is probably very important to develop new SC superalloys with an excellent combination of high creep strength and very good oxidation resistance. We also inspected the microstructures of alloy-B after the creep test. No TCP phase was observed in it, which was in contrast to CMSX-10 [1] and MC2 [19]. Thus, the phase stability of alloy-B was excellent indeed.

It was noted here that alloy B possessed much higher creep strength than the 2nd generation superalloy, CMSX-4, as shown in Fig. 14. It had about $20^{\circ} \mathrm{C}$ higher temperature capability than CMSX-4, while exhibiting excellent hot corrosion resistance and oxidation resistance as shown in Fig. 6 and Figs.8, 9 and 10.

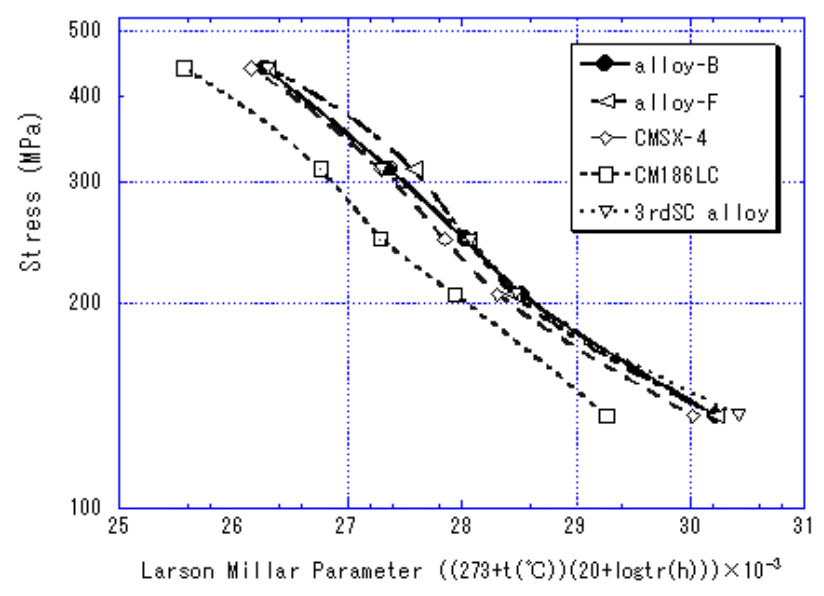

Fig. 14. Creep rupture strength of alloy B, alloy F and the reference alloys.

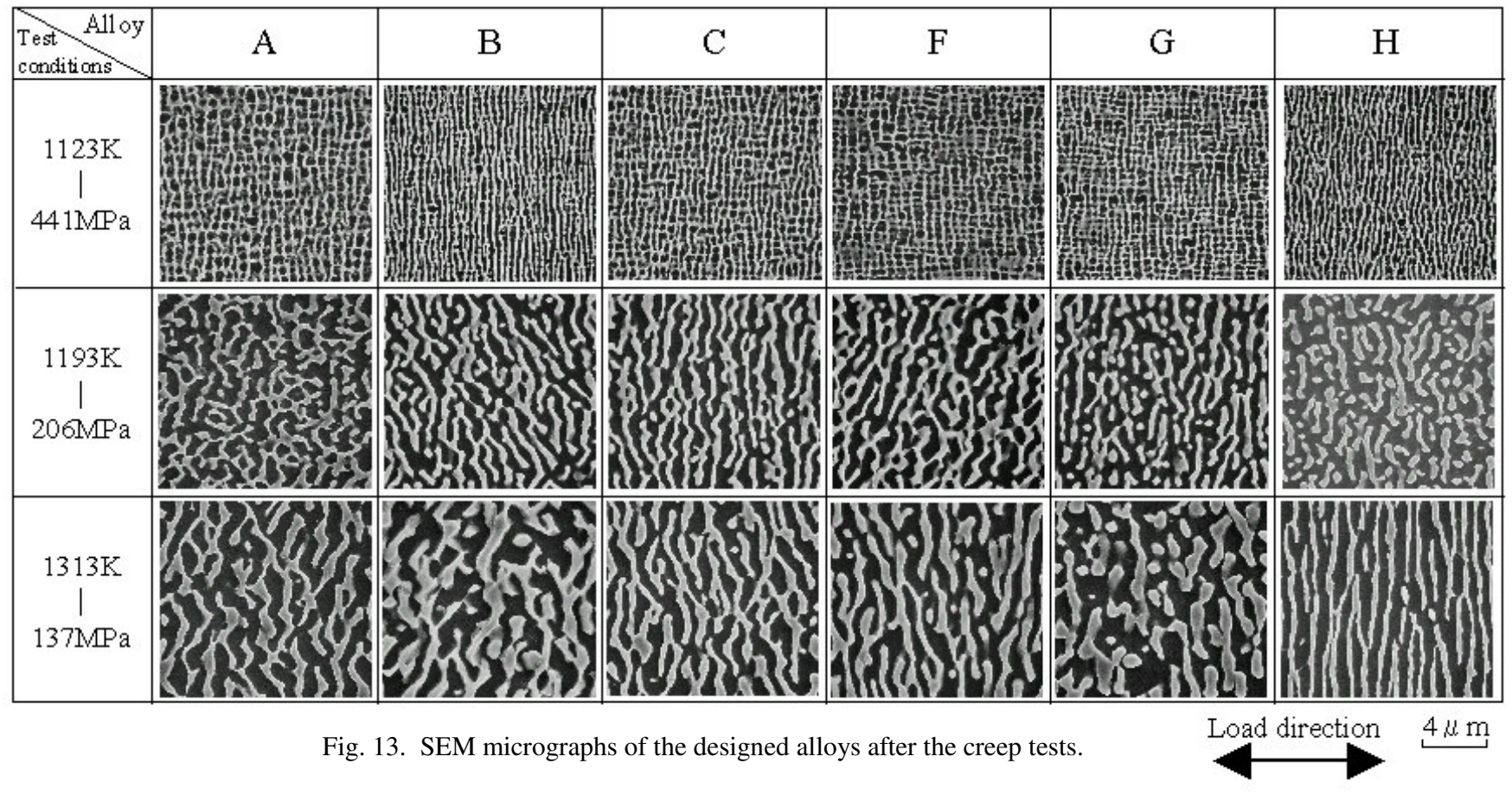

\section{$\underline{\text { Oxidation Resistance }}$}

According to our previous study [15], the condensed $\mathrm{Al}_{2} \mathrm{O}_{3}$ layer tends to be formed predominantly on the alloy surface in the first stage of oxidation compared to $\mathrm{TiN}, \mathrm{TiO}_{2}, \mathrm{AlN}$. Here, the difference in the free energy of formation between $\mathrm{TiO}_{2}$ and $\mathrm{Al}_{2} \mathrm{O}_{3}$ is not so large Therefore when the Ti content is high, $\mathrm{TiO}_{2}$ and $\mathrm{Al}_{2} \mathrm{O}_{3}$ oxides are formed competitively, As a result, neither $\mathrm{Al}_{2} \mathrm{O}_{3}$ nor $\mathrm{TiO}_{2}$ condensed layer is formed on the alloy surface. In this sense, it is important to control the $\mathrm{Ti} / \mathrm{Al}$ compositional ratio in order to keep oxidation resistance good. In this study, all the designed alloys had almost the same Ti/Al compositional ratio, so it was supposed that the oxidation resistance was similar among the alloys. However, this was not the case. The results of oxidation tests varied greatly among the alloys. This is partially due to the presence of a large amount of $\mathrm{Re}, 3.6 \%-5.4 \%$, in the alloys, because $\mathrm{Re}$ is an element that can deteriorate oxidation resistance[16].

Also, it was found from the present experiment that the oxidation resistance changed depending, not only on the Ti/Al compositional ratio, but also on the contents of $\mathrm{Mo}, \mathrm{Cr}, \mathrm{W}$ and $\mathrm{Re}$ in the alloy. As shown in Fig. 8, a large mass reduction was observed only in the Mo-containing alloys exposed for 10,000 
hours at $1193 \mathrm{~K}$. Among them, alloy J showed the largest mass reduction of $22 \mathrm{mg} / \mathrm{cm}^{2}$. This is probably interpreted as due to the highest amount of Mo, $1.4 \%$, and the least amount of $\mathrm{Al}, 5.1 \%$, in the alloy. As for alloys I and $\mathrm{H}$, the mass reduction started after about 4,000 hours, and it kept increasing. The value measured after 10,000 hours was $-17.1 \mathrm{mg} / \mathrm{cm}^{2}$ for alloy I and $-9.0 \mathrm{mg} / \mathrm{cm}^{2}$ for alloy $\mathrm{H}$. These results are partially due to the presence of a relatively large amount of detrimental elements to oxidation resistance, since alloy I contained $0.6 \% \mathrm{Mo}$ and $5.4 \% \mathrm{Re}$, and alloy $\mathrm{H}$ contained $0.8 \% \mathrm{Mo}$ and $5.2 \% \mathrm{Re}$. In addition, poor oxidation resistance was seen in a reference alloy, $14 \% \mathrm{CrCC}$. In this case, thick oxidation scales of $\mathrm{Cr}_{2} \mathrm{O}_{3}$ were formed on the alloy surface and they flaked off readily [16].

It is well known that Mo is an element to form volatile $\mathrm{MoO}_{3}$ at high temperatures. In accordance with this Mo effect, as shown in Fig. 9 and Fig. 10, any Mo-containing alloys had poorer oxidation resistance than the Mo-free alloys, nearly independent of the contents of the refractory elements in the alloys. SEM micrographs and the corresponding semi-quantitative EDX analyses of surface scale are shown in Fig. 15 for the alloy B and the alloy F. Despite that both alloys were Mo-free, alloy B had the highest oxidation resistance, whereas alloy $\mathrm{F}$ had relatively poor resistance among the designed alloys. The differences in their chemical compositions were mainly the $\mathrm{Cr}$ and $\mathrm{W}$ contents between them. Nevertheless, the appearance of the oxidation scale was very different between them. In case of the alloy $\mathrm{F}$, the most inner scale of $\mathrm{Al}_{2} \mathrm{O}_{3}$ eroded the base alloy without forming the dense layer. On the other hand, in the case of alloy B, the inner

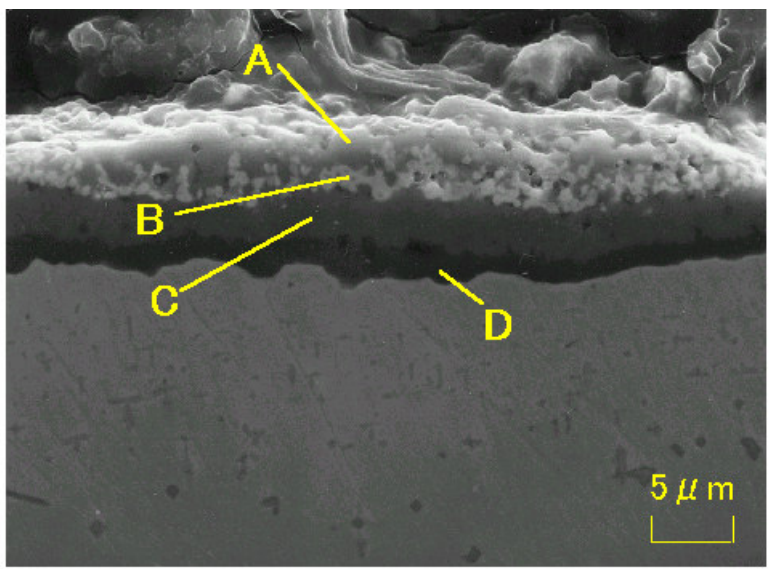

(mass $\%)$

\begin{tabular}{|c|r|r|r|c|}
\hline Elements & \multicolumn{1}{|c|}{$\mathrm{A}$} & \multicolumn{1}{c|}{$\mathrm{B}$} & $\mathrm{C}$ & $\mathrm{D}$ \\
\hline $\mathrm{O}$ & 44.1 & 24.9 & 35.6 & 40.1 \\
\hline $\mathrm{Al}$ & 5.4 & 1.5 & 23.4 & 44.1 \\
\hline $\mathrm{Ti}$ & 1.6 & 1.9 & & \\
\hline $\mathrm{Cr}$ & 22.4 & 6.2 & 5.1 & 1.9 \\
\hline $\mathrm{Co}$ & 9.9 & 3.1 & 6.6 & 2.3 \\
\hline $\mathrm{Ni}$ & 14.5 & 10.7 & 26.9 & 9.4 \\
\hline $\mathrm{Ta}$ & 1.4 & 46.2 & 1.7 & 0.2 \\
\hline $\mathrm{W}$ & 0.7 & 5.6 & 0.7 & 2.0 \\
\hline
\end{tabular}

(a)Alloy B most $\mathrm{Al}_{2} \mathrm{O}_{3}$ scale was formed in a condensed way, so it worked as a barrier to the oxidation, resulting in the high oxidation resistance of alloy B.

In the case of the six Mo-free alloys from A to F, the contents of $\mathrm{Ti}, \mathrm{Co}$ and $\mathrm{Al}$ were almost the same, but the contents of $\mathrm{Cr}, \mathrm{Ta}, \mathrm{W}$ and Re were different among them. This caused differences in the inner oxidation scales among them. For example, alloy B contained $0.8 \%$ Re higher than alloy $\mathrm{C}$, and alloy $\mathrm{D}$ contained $1.5 \% \mathrm{Cr}$ lower and $0.5 \% \mathrm{~W}$ higher than alloy E. However, the former alloy, B (or D), showed higher oxidation resistance than the latter alloy, C (or E). In other words, the higher Recontaining alloy $\mathrm{B}$ was superior in the oxidation resistance to the lower Re-containing alloy $\mathrm{C}$. This seemed to be contradictory to the fact that $\mathrm{Re}$ is a detrimental element to the oxidation. The reason still remains unclear at the moment. The chemical interactions between the elements, $\mathrm{Cr}, \mathrm{W}, \mathrm{Ta}$ and $\mathrm{Re}$, should be investigated to elucidate the oxidation mechanism of the Ni-based superalloys.

Two reference alloys, CMSX-4 and CM186LC, showed the least mass change and hence they possessed good oxidation resistance. These alloys contained only $3 \% \mathrm{Re}$, and high $\mathrm{Al}$ contents $(5.6 \% \mathrm{Al}$ for CMSX-4 and 5.7\% Al for CM186LC). In addition, CM186LC contained $1.4 \% \mathrm{Hf}$, because this is a DS alloy into which $\mathrm{Hf}$ is added occasionally in order to increase the surface stability against oxidation. For these reasons, the reference alloys had good oxidation resistance.

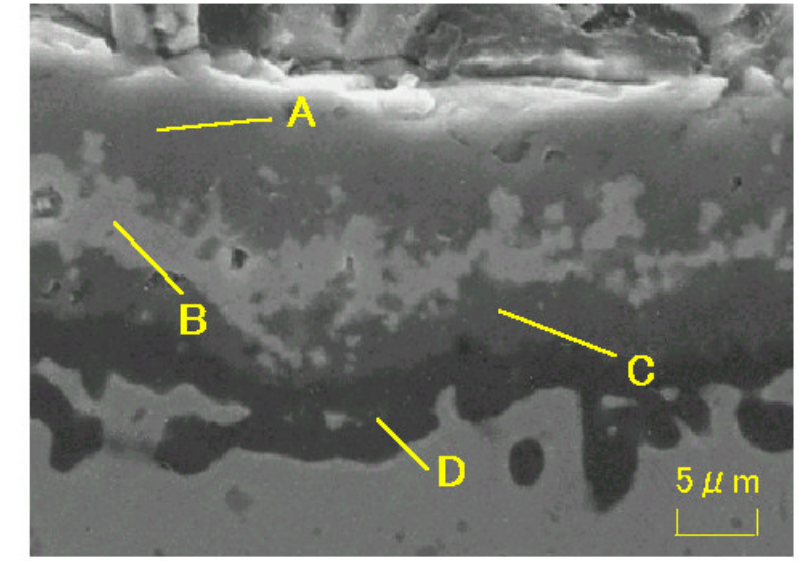

\begin{tabular}{|c|r|r|r|r|}
\multicolumn{1}{|c}{ (mass\%) } \\
\hline Elements & \multicolumn{1}{c|}{$\mathrm{A}$} & \multicolumn{1}{c|}{$\mathrm{B}$} & \multicolumn{1}{c|}{$\mathrm{C}$} & \multicolumn{1}{c|}{$\mathrm{D}$} \\
\hline $\mathrm{O}$ & 33.4 & 21.6 & 35.5 & 42.4 \\
\hline $\mathrm{Al}$ & 3.0 & 0.6 & 23.5 & 45.5 \\
\hline $\mathrm{Ti}$ & 0.6 & 5.5 & 0.3 & \\
\hline $\mathrm{Cr}$ & 35.9 & 8.2 & 4.6 & 1.0 \\
\hline $\mathrm{Co}$ & 15.8 & 1.9 & 8.3 & 1.6 \\
\hline $\mathrm{Ni}$ & 11.3 & 6.8 & 25.0 & 7.6 \\
\hline $\mathrm{Ta}$ & & 45.4 & 2.3 & 0.3 \\
\hline $\mathrm{W}$ & & 10.0 & 0.6 & 1.5 \\
\hline
\end{tabular}

(b)Alloy $\mathrm{F}$

Fig. 15. SEM micrographs and the corresponding semi-quantitative EDX analyses of surface scale taken from the cross section of alloy B and alloy F after the continuous oxidation test at $1313 \mathrm{~K}$ for 3600 hours. 


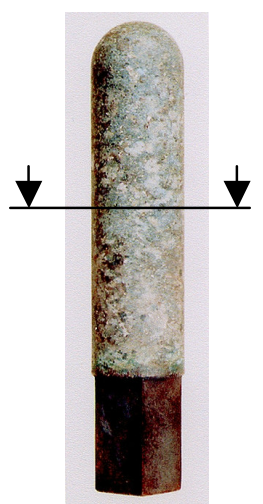

Cutting position

B-1

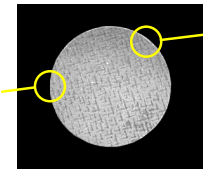

Analyses points

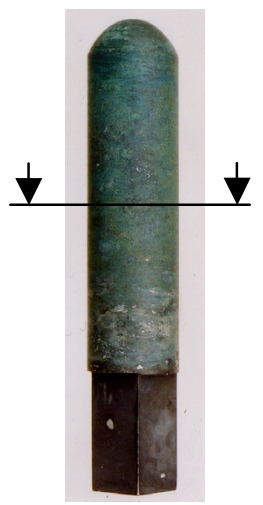

Cutting position

F-1

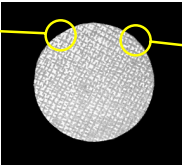

$\underline{\text { Analyses points }}$

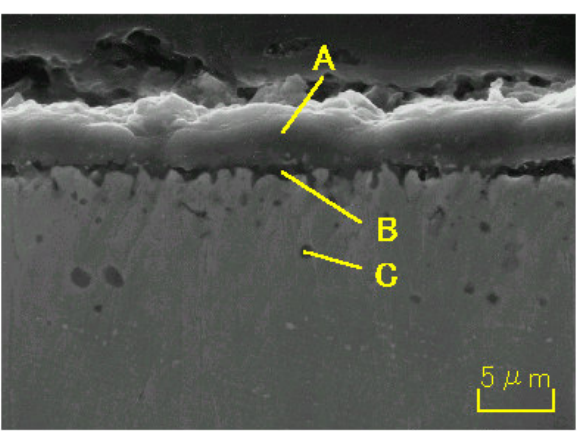

\begin{tabular}{|c|r|r|r|}
\multicolumn{4}{|c|}{ (mass\%) } \\
\hline Elements & \multicolumn{1}{|c|}{$\mathrm{A}$} & \multicolumn{1}{c|}{$\mathrm{B}$} & \multicolumn{1}{c|}{$\mathrm{C}$} \\
\hline $\mathrm{O}$ & 36.9 & 28.1 & 4.8 \\
\hline $\mathrm{S}$ & & & \\
\hline $\mathrm{Al}$ & 47.9 & 26.4 & \\
\hline $\mathrm{Ti}$ & 2.0 & 0.5 & 11.6 \\
\hline $\mathrm{Cr}$ & 2.9 & 3.4 & 23.2 \\
\hline $\mathrm{Co}$ & 0.8 & 6.1 & 8.5 \\
\hline $\mathrm{Ni}$ & 4.3 & 31.0 & 46.2 \\
\hline $\mathrm{Ta}$ & 4.0 & 2.0 & 2.9 \\
\hline $\mathrm{W}$ & 1.3 & 2.5 & 3.0 \\
\hline \multicolumn{3}{|c}{}
\end{tabular}

( a ) Alloy B-point B-1

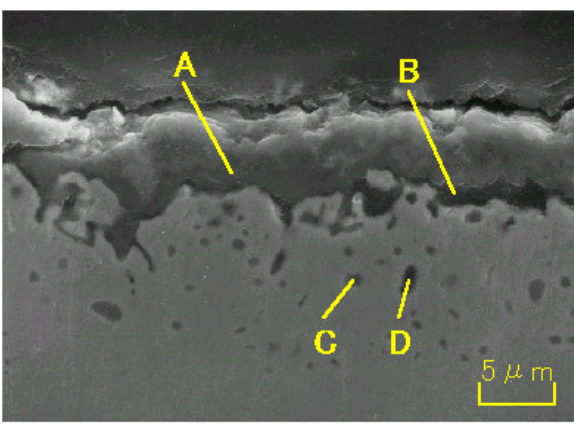

$(\operatorname{mass} \%)$

\begin{tabular}{|c|r|r|r|r|}
\hline Elements & \multicolumn{1}{|c|}{$\mathrm{A}$} & \multicolumn{1}{c|}{$\mathrm{B}$} & $\mathrm{C}$ & \multicolumn{1}{c|}{$\mathrm{D}$} \\
\hline $\mathrm{O}$ & 46.5 & 18.6 & & \\
\hline $\mathrm{S}$ & & & 18.0 & \\
\hline $\mathrm{Al}$ & 38.8 & 42.6 & & \\
\hline $\mathrm{Ti}$ & 0.7 & 0.7 & 10.5 & 0.2 \\
\hline $\mathrm{Cr}$ & 5.0 & 5.4 & 15.2 & 3.2 \\
\hline $\mathrm{Co}$ & 1.1 & 4.0 & 7.3 & 13.0 \\
\hline $\mathrm{Ni}$ & 4.5 & 23.7 & 44.3 & 77.7 \\
\hline $\mathrm{Ta}$ & 2.6 & 1.4 & 1.8 & 1.2 \\
\hline $\mathrm{W}$ & 0.7 & 3.7 & 3.0 & 4.8 \\
\hline
\end{tabular}

(c ) Alloy F-point F-1

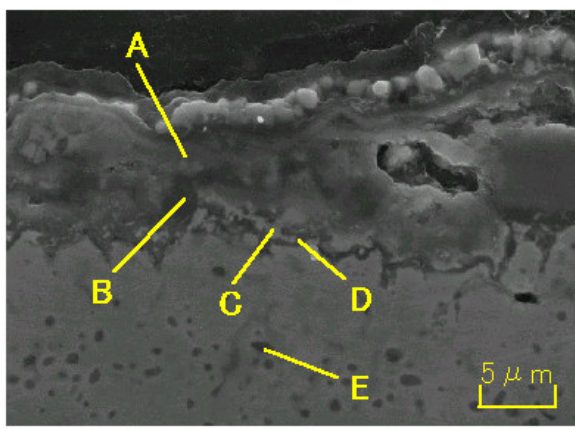

$(\operatorname{mass} \%)$

\begin{tabular}{|c|r|r|r|r|r|}
\hline Elements & \multicolumn{1}{c|}{$\mathrm{A}$} & \multicolumn{1}{c|}{$\mathrm{B}$} & \multicolumn{1}{c|}{$\mathrm{C}$} & \multicolumn{1}{c|}{$\mathrm{D}$} & \multicolumn{1}{c|}{$\mathrm{E}$} \\
\hline $\mathrm{O}$ & 35.3 & 55.9 & 13.2 & 18.7 & 4.2 \\
\hline $\mathrm{S}$ & & & & & 7.3 \\
\hline $\mathrm{Al}$ & & & & 19.3 & \\
\hline $\mathrm{Ti}$ & 6.4 & 3.7 & 0.9 & 0.3 & 0.4 \\
\hline $\mathrm{Cr}$ & 13.2 & 5.5 & 2.7 & 2.4 & 11.3 \\
\hline $\mathrm{Co}$ & 12.4 & 5.4 & 8.0 & 6.8 & 9.8 \\
\hline $\mathrm{Ni}$ & 20.5 & 19.8 & 53.9 & 43.6 & 61.0 \\
\hline $\mathrm{Ta}$ & 6.8 & 0.8 & 4.4 & 2.7 & 1.8 \\
\hline $\mathrm{W}$ & 5.4 & 8.9 & 16.9 & 6.2 & 4.3 \\
\hline
\end{tabular}

( b ) Alloy B-point B-2

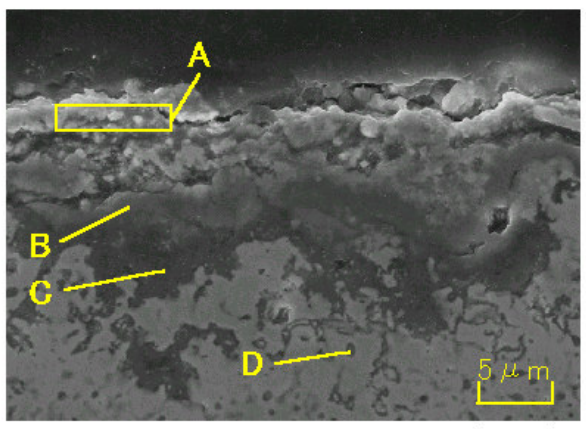

$(\operatorname{mas} s \%)$

\begin{tabular}{|c|r|r|r|r|}
\hline Elements & \multicolumn{1}{c|}{$\mathrm{A}$} & \multicolumn{1}{c|}{$\mathrm{B}$} & \multicolumn{1}{c|}{$\mathrm{C}$} & \multicolumn{1}{c|}{$\mathrm{D}$} \\
\hline $\mathrm{O}$ & 24.2 & 27.9 & 15.4 & 4.9 \\
\hline $\mathrm{S}$ & & & & 9.1 \\
\hline $\mathrm{Al}$ & 3.9 & 12.1 & 17.0 & 2.3 \\
\hline $\mathrm{Ti}$ & 6.2 & 16.5 & 0.7 & 2.8 \\
\hline $\mathrm{Cr}$ & 3.5 & 6.1 & 3.1 & 13.5 \\
\hline $\mathrm{Co}$ & 8.5 & 8.7 & 7.5 & 8.8 \\
\hline $\mathrm{Ni}$ & 32.7 & 21.1 & 45.1 & 50.5 \\
\hline $\mathrm{Ta}$ & 18.4 & 6.3 & 3.4 & 3.3 \\
\hline $\mathrm{W}$ & 2.6 & 1.4 & 7.8 & 4.8 \\
\hline
\end{tabular}

( d ) Alloy F-point F-2

Fig. 16. SEM micrographs and the corresponding semi-quantitative EDX analyses of surface scale taken from the cross section of alloy $\mathrm{B}$ and alloy $\mathrm{F}$ after the hot corrosion burner rig test.

\section{Hot Corrosion Resistance}

All the designed alloys exhibited superior hot-corrosion resistance. In this respect, the designed alloys were comparable to the reference alloy, CMSX-4. Also, the hot-corrosion resistance did not depend on the Mo content in the alloy. The SEM micrographs and the results of semi-quantitative EDX analyses on the surface scale are shown in Fig. 16 for alloys B and F. There were two different parts in the hot zone of each alloy, and both the damaged part (named B-2 or F-2 in the figure) and the sound part (named B-1 or F-1 in the figure) were examined with these two alloys after the burner rig test. As explained earlier, both the alloys had good hot corrosion resistance. In fact, the mass change of alloy $\mathrm{F}$ was close to $0 \mathrm{mg} / \mathrm{cm}^{2}$, but this does not mean that alloy-F was intact, but the scale was flaking-off more rapidly in alloy- $\mathrm{F}$ than in alloy B, resulting in no superficial mass change in alloy-F. In our previous study [15], it was shown that sulfuration occurs first prior to oxidation, and then sulfides are oxidized. It is generally known that such sulfuration and subsequent oxidation reactions take place alternately and repeatedly, and the surface layers penetrate deeply into the base alloy[15,17]. Therefore, the hotcorrosion resistance will be improved if the sulfuration reaction is suppressed in some ways. For example, when the alloy contains $\mathrm{Ti}$ at a certain level, a condensed $\mathrm{TiO}_{2}$-rich layer will 
form quickly on the specimen surface owing to the higher stability of $\mathrm{TiO}_{2}$ than $\mathrm{Cr}_{2} \mathrm{O}_{3}$. In such a case, $\mathrm{Cr}$ is never oxidized because of the higher dissociation pressure of $\mathrm{Cr}_{2} \mathrm{O}_{3}$ than $\mathrm{TiO}_{2}$, but instead $\mathrm{Cr}$ interacts with sulfur to form a sulfide under the oxide layer. As a result, sulfuration does not proceed into the base alloy anymore, resulting in the maintenance of good hot corrosion resistance [15]. From the EDX analyses of the designed alloys, it was evident that the $\mathrm{Cr}$ concentration became very high in the region where sulfur was detected in the corrosive area. Although the $\mathrm{Cr}$ content, $4 \%$ $6.5 \%$, in the designed alloys was not so high, the $\mathrm{CrS}$ layer was formed like in Cr-rich superalloys.

\section{Conclusions}

Ni-based single crystal superalloys were designed in order to develop single crystal alloys which are usable for the first stage blades in the $1500^{\circ} \mathrm{C}$ or even higher class industrial gas turbine with high efficiency. A series of experiments was conducted on the tensile strength, creep strength, hot corrosion resistance, hot oxidation resistance and castability. The results are summarized as follows:

1. Most of the designed alloys had high tensile strength, excellent creep strength, hot corrosion resistance and stable microstructure. No TCP phases or undesirable phases were observed even after a long term creep test. It was also found that Mo is not a critical element to enhance the creep strength of the superalloy.

2. Mo-free alloys exhibited higher oxidation resistance than Mo-containing alloys. Also, it was possible to improve oxidation resistance greatly even in the alloys containing more than $4 \%$ Re by optimizing the contents of the other refractory elements such as $\mathrm{Cr}, \mathrm{W}$ and $\mathrm{Ta}$.

3. There was no inherent problem of castability in the Mo-free alloys. A single crystal model bucket $170 \mathrm{~mm}$ in length was grown for use in the first stage blade of $25 \mathrm{MW}$ class industrial gas turbine.

4. Some of the designed alloys possessed about $20^{\circ} \mathrm{C}$ higher temperature capability than the second generation superalloy.

\section{Acknowledgments}

The authors would like to thank Dr.Y.Fukui and Dr.Y.Kojima (Hitachi Reseach Laboratory, Hitachi Co., Ltd.) for their valuable advice and helpful discussions on the present study.

\section{References}

[1] W. S. Walston et al., "Rene N6: Third Generation Single Crystal Superalloy", Superalloys 1996, Eds. R.D. Kissinger et al., TMS, Warrendale, 1996, pp.27-34.

[2] G.L.Erickson, "The Development and Application of CMSX10", ditto, pp.35-44.

[3] K.Matsugi, Y.Murata, M.Morinaga and N.Yukawa, "Realistic Advancement for Nickel-Based Single Crystal Superalloys by the d-Electrons Concept", Superalloys 1992, edited by S.D.Antolovich et al., The TMS, 2000, pp.307-316.

[4] R.Kehlhofer, "Power Engineering-Status and Trends", Materials for Advanced Power Engineering 1998, Eds. J.
Lecomte-Beckers, et al., Forchungszentrum, Jülich, 1998, pp.3-17. [5] A.Yoshinari, R.Hashizume, Y.Murata and M.Morinaga "Development of the third generation single crystal superalloy for power generation gas turbines": Proc.8th Int.Gas.Turbine. Conf.2003 Tokyo(IGTC2003), ed . by Toshinori Watanabe, Gas Turbine Society of Japan, Tokyo.

[6] M.Morinaga, N.Yukawa and H.Adachi, "Alloying Effect on the Electronic Structure of $\operatorname{Ni3Al}\left(\gamma^{\prime}\right)$ ", J. Phys. Soc. Japan, 53 (1984), 653-663.

[7] Md.Moniruzzaman, Y.Murata, M.Morinaga, R.Hashizume, A.Yoshinari and Y.Fukui, "Alloy Design of Ni-Based Single Crystal Superalloys for the Combination of Strength and Surface Stability at Elevated Temperatures”, ISIJ International, 43(2003), 1244-1252.

[8] M.Morinaga, N.Yukawa, H.Ezaki and H.Adachi,"Solid Solubilities in Transition-Metal Based FCC Alloys", Phil. Mag., A51(1985), 223-246.

[9] M.Morinaga, N.Yukawa, H.Ezaki and H.Adachi,"Solid Solubilities in Nickel-Based FCC Alloys", Phil. Mag., A51(1985), 247-252.

[10] M.Morinaga, Y.Murata and H.Yukawa,'Recent Progress in the New PHACOMP Approach", Materials Design Approaches and Experiences, edited by J.-C.Zhao, M.Fahrmann and T.M.Pollock, TMS(The Minerals,Metals \& Materials Society),2001, pp.15-27.

[11] M.Morinaga, N.Yukawa and H.Adachi, "New PHACOMP and Its Application to Alloy Design”, Superalloys 1984, edited by M. Gell, MC.S. Kortovich, R.H.Bricknell, W. B. Kent and J.F. Radavich, The Metallurgical Society of AIME, 1984, pp.523-532. [12] Y.Murata, S.Miyazaki, M.Morinaga and R.Hashizume, "Hot Corrosion Resistant and High Strength Nickel-Based Single Crystal and Directionally-Sosidified Superalloys Developed by the d-Electrons Concept", Superalloys 1996, edited by R.D.Kissinger et al., The TMS, 1996, pp.61-70.

[13] H.Harada, "Materials Design", Report of the 123 Committee on Heat-Resisting Metals and Alloys, Japan Society for the Promotion of Science, 28(1997),185-196.

[14] T.Hino, Y.Yoshioka, Y.Koizumi, T.Kobayashi and H.Harada, "TMS-82+: A High Strength Ni-Base Single Crystal Superalloy", Materials for Advanced Power engineering 2002, ed. by J.Lecomte-Beckers et al., Forchungszentrum, Julich GmbH, 2002, pp.303-312.

[15] Y.Murata, R.Hashizume, A.Yoshinari, N.Aoki, M.Morinaga and Y.Fukui, "Alloying Effect on Surface Stability and Creep Strength of Nickel Based Single Crystal Superalloys containing 12 mass\%Cr", Superalloys 2000, edited by T.M.Pollock et al., The TMS, 2000, pp.285-294.

[16] Md.Moniruzzaman, M.Maeda, Y.Murata and M.Morinaga, "Degradation of High-Temperature Oxidation Resistance for NiBased Alloys by Re Addition and the Optimization of Re/Al Content”, ISIJ International, 43(2003), 386-393.

[17] F.S.Pettit and G.H.Meier, "Oxidation and Hot Corrosion of Superalloys", Superalloys 1984, edited by M.Gell et al., The Metallurgical Society of AIME, 1984, pp.651-687.

[18]:T.M.Pollock et al., "Grain defect formation during directional solidification of nickel single crystals ", Superalloys 1992, Eds. R.D. S. D. Antolovich et al., TMS, Warrendale, 1992, pp.125-134. [19]: M. Pessah et al., "Effect of $\mu$ phase on the mechanical properties of a nickel-base single crystal superalloy", Superalloys 1992, Eds. R.D. S. D. Antolovich et al., TMS, Warrendale, 1992, pp.567-576. 